\title{
EFFECT OF FERMENTATION ON STRUCTURAL CHARACTERISTICS AND BIOACTIVE COMPOUNDS OF BEE-POLLEN BASED FOOD
}

\author{
Carlos M. Zuluaga-Dominguez* \\ Marta Quicazan \\ Universidad Nacional de Colombia \\ *corresponding author: cmzuluagad@unal.edu.co \\ Received: 10 July 2018; accepted: 03 January 2019
}

\begin{abstract}
A b stract
Bee-pollen is a product of the hive which has had a growth in consumption in recent years due to the recognition of its nutritional and bioactive potential. However, several reports have shown that the external structure of the grain limits the absorption of nutrients in the human gastrointestinal tract. A structural modification could be achieved through fermentative processes, favoring the release of compounds found inside this food, in addition to obtaining a product with potential probiotic characteristics. The objective of this work was to evaluate how fermentation through the inclusion of yeasts of the species Saccharomyces cerevisiae, bacteria of species Lactobacillus plantarum or a commercial culture Choozit ${ }^{\circledR}$ affeccted such parameters as Scanning Electron Microscopy (SEM), Differential Scanning Calorimetry (DSC), phenolic compounds, flavonoids and antioxidant activity. The results found that the use of consortia between yeast and lactic acid bacteria significantly increased in such characteristics as total phenolics and antioxidant activity by $31 \%$ and $39 \%$ respectively. The analysis by DSC showed an increase in the heat flow of the fermented products compared to fresh bee-pollen, which could indicate structural modification caused by the activity of microorganisms, a fact made visible through micrographs obtained by Scanning Electron Microscopy.
\end{abstract}

Keywords: antioxidants, beekeeping, bioprocess, exine, functional food, novel foods

\section{INTRODUCTION}

Pollen is the main source of protein and fat for bees (Almeida-Muradian et al., 2005), and given its nutritional characteristics, a proper hive management encourages the collection of bee-pollen for human consumption. This food is known for its considerable protein content, dietary fiber, fat and such minerals as $\mathrm{K}, \mathrm{Ca}, \mathrm{Mg}$, all of which vary in concentration depending on the geographical and botanical origin (Fuenmayor et al., 2014). In addition, biologically active substances have been reported in bee-pollen, mainly phenolic compounds and flavonoids (Bogdanov, 2011), which some studies have associated with health benefits (Leja et al., 2007).

Regardless of the characteristics of bee-pollen, there are reports on the reduced availability of nutrients and bioactive compounds once bee-pollen is ingested (Campos et al., 2010; Bogdanov, 2011; Zuluaga, Serrato, \& Quicazan, 2015). This is mainly due to the strong chemical structure that covers the outer layer of the grain known as exine (Bogdanov, 2011). Those reports suggest bee-pollen must undergo transformation processes before human consumption in order for its shelf life to increase, and for its nutritional and functional quality indicators to improve. It is known that in hives, bees rarely consume pollen directly but do it after it has been stored in cells in order for it to go it through a biochemical transformation process, mediated by lactic acid bacteria, and convert into a product known as "bee-bread" (Del Risco et al., 2012; Salazar-González \& Díaz-Moreno, 2016). Bee-bread, compared to bee-pollen, may be better tolerated by the human organism (Vamanu et al., 2010) because it has an average of $3 \%$ of lactic acid, a greater content of vitamin $\mathrm{K}(6500 \mathrm{mg} / \mathrm{kg}$ and $7400 \mathrm{mg} / \mathrm{kg}$ in bee-pollen and bee-bread, respectively) and higher values of aminoacids (Andelkovic et al., 2012). Other studies have described how the fermentation process is influenced by bacterial flora of which some species of lactic acid bacteria can be found: 
Lactobacillus kunkeii, Lactobacillus jensenii, Lactobacillus fructosus and Lactobacillus plantarum (Gilliam, 1979a; Vasquez et al., 2009).

Moreover, literature mentions that this natural modification improves the nutritional and bioactive characteristics of bee-pollen (Gilliam, 1979a; Bogdanov, 2011). However, the associated microbiota is heterogeneous and, if bee-bread is to be considered for marketing, under these natural conditions it is difficult to ensure production batches with the same nutritional quality. In addition, it has been reported that the presence of high lactic-acid levels in bee-bread difficult the possibility of storage for long periods, being a food with a short shelf life (Kieliszek et al., 2018).

In this sense, studies have been performed in order to develop a process similar to that made by bees in the hive at laboratory level under controlled conditions. This not only helps supervising the process conditions but also facilitates checking the quality of the final product, which could be maintained steadily over time. Process simulations for obtaining analogous bee-bread products using Lactobacillus acidophilus (Vamanu et al., 2006) or Lactobacillus plantarum (Vamanu et al., 2008) have been reported. Satisfactory results for biomass growth and synergistic effects were found when Lactic Acid Bacteria (LAB) strains are combined (Fuenmayor, 2009; Zuluaga, Serrato, \& Quicazan, 2015; Salazar-González \& Díaz-Moreno, 2016), and even when external nutrients were supplied to such substrates as inulin and lactulose (Vamanu et al., 2010).

In spite of this, there are still some unknowns to be able to develop the process of bee-pollen fermentation at an industrial level. Not only in bee-pollen, but in other cases such as cocoa, coffee, tea, or kefir there is a microbiological succession where the first colonizers are yeasts (Gilliam, 1979b; Avallone et al., 2001; Schwan \& Wheals 2004; Teoh, Heard, \& Cox, 2004; LopitzOtsoa et al., 2006), followed by a phase where bacteria appear, mainly lactic acid bacteria; nevertheless, in the case of bee-pollen the effect of yeasts inclusion has not been considered. Another important aspect is related to the possibility of using existing commercial microbiological cultures as a cost reduction strategy, however, it is necessary to corroborate their effectiveness when they are used in plant-derived matrices such as bee-pollen.

In this order, the aim of this work was to evaluate the effect that different ATCC strains and commercial yeast and $L A B$ cultures have on the structural and physicochemical characteristics of bee-pollen, when fermentation processes are carried out in order to obtain a food similar to bee-bread. Differential Scanning Calorimetry (DSC) and Scanning Electron Microscopy (SEM) described structural modifications caused by the bioprocess, and variations in acidity, antioxidant activity and the content of phenolic compounds and flavonoids were evaluated. This work aims to contribute towards the development of a standardized procedure for bee-pollen fermentation. It could be scaled and applied in food industry through the obtaining of a standard product and the inclusion of economic and ready-to-use microbiological cultures.

\section{MATERIAL AND METHODS}

\section{Samples}

Bee-pollen

Bee-pollen samples were taken from the Cundiboyacense high plateau, the most important beekeeping region in Colombia, located at an altitude over 2500 m.a.s.l. on the central part of the Colombian eastern Andes. Palynological characterization revealed that Hypochaeris and Brassica were the most abundant plant genus. Bee-pollen was stored in bags and kept in refrigeration $\left(4^{\circ} \mathrm{C} \pm 1^{\circ} \mathrm{C}\right)$ until assays.

\section{Lactic acid bacteria cultures}

ATCC and commercial lactic acid bacteria cultures were employed in this study. The organism Lactobacillus plantarum ATCC 8014 (Kwik Stik ${ }^{\top M}$, Minnesota, USA) and a Choozit ${ }^{\circledR}$ MY800 commercial culture (Danisco, Denmark) were used. Choozit' is a mixture of microorganisms Streptococcus thermophilus, Lactobacillus delbrueckii subsp. lactis and Lactobacillus delbrueckii subsp. bulgaricus. Both cultures were used in this work since they had been proven 
to give satisfactory results in previous studies (Fuenmayor, 2009; Zuluaga, Serrato, \& Quicazan, 2015; Salazar-González \& Díaz-Moreno 2016). All cultures were kept frozen in their commercial presentation at $-20^{\circ} \mathrm{C} \pm 3^{\circ} \mathrm{C}$.

Yeast cultures

The organism Saccharomyces cerevisiae ATCC 9763 (Kwik Stik ${ }^{T M}$, Minnesota, USA) and an available baker's yeast of species Saccharomyces cerevisiae (Levapán, Colombia) were employed in this study. All cultures were kept frozen in their commercial presentation at $-20^{\circ} \mathrm{C}$ $\pm 3^{\circ} \mathrm{C}$

\section{Experimental procedure}

In total, six different fermentation tests were carried out. Two tests were performed by inoculating yeasts, both ATCC and the commercial culture. Another two included ATCC lactic acid bacteria and commercial culture. Finally, the remaining two were conducted through the inoculation of yeast-lactic acid bacteria consortia, from ATCC strains and commercial cultures, respectively.

\section{LAB activation}

An ATTC strain was taken from a porous bed bound to the bacteria and submerged in $9 \mathrm{~mL}$ of MRS (Man, Rogose, Sharpe) broth (Scharlau, Spain) and incubated at $35^{\circ} \mathrm{C}$ for $24 \mathrm{~h}$ in anaerobic conditions. The commercial culture activation was done by weighing $0.2 \mathrm{~g}$ of lyophilized powder mixed with $9 \mathrm{~mL}$ of MRS broth and incubated at $35^{\circ} \mathrm{C}$ for $24 \mathrm{~h}$ in anaerobic conditions. Then, the strains were spread onto MRS agar plates, allowing colony growth for $24 \mathrm{~h}$ at $35^{\circ} \mathrm{C}$. The grown colonies were suspended in a sterile nutrient broth $0.1 \%$ with turbidity equivalent to a 5 McFarland standard.

\section{Yeast activation}

An ATTC strain was activated from a porous bed bound to the yeast, and the commercial yeast was activated from $1 \mathrm{~g}$ of lyophilized powder. In each case, the strain was mixed in $9 \mathrm{~mL}$ of yeast special broth, elaborated from peptone (2\% $w / v)$, glucose $(2 \% \mathrm{w} / \mathrm{v})$ and yeast extract $(1 \%$ $w / v)$ and distilled water, and incubated at $25^{\circ} \mathrm{C}$ for $24 \mathrm{~h}$ under aerobic conditions. The strain was then spread onto PDA (potato, dextrose, agar) agar plates, allowing colony growth for $24 \mathrm{~h}$ at $25^{\circ} \mathrm{C}$. The grown colonies were suspended in a sterile nutrient broth $0.1 \%$ with turbidity equivalent to a 5 McFarland standard.

\section{Pre-inoculum incubation}

In order to avoid reduced biomass production, prior to fermentation, $1 \mathrm{~mL}$ of the active strain was suspended in a solution containing $1 \mathrm{~g}$ of bee-pollen and $9 \mathrm{~mL}$ of MRS broth in the case of lactic acid bacteria or special broth for yeasts. The pre-inoculum was incubated at $35^{\circ} \mathrm{C}$ for $24 \mathrm{~h}$ under anaerobic conditions for bacteria and at $25^{\circ} \mathrm{C}$ for $24 \mathrm{~h}$ under aerobic conditions for yeasts.

Fermentation

For each preparation, $200 \mathrm{~g}$ of substrate was prepared through employing a 1:1 ratio of bee-pollen and water. The substrates were served in $250 \mathrm{~mL}$ flasks, which had been previously sealed and sterilized at $121^{\circ} \mathrm{C}$ for 15 min. It was then added to the inoculum and left to incubate at $37^{\circ} \mathrm{C}$ for $72 \mathrm{~h}$. Four experiments were conducted, each one with three replicates.

\section{Microbiological monitoring of fermentation}

The plate count of the colonies at different sampling points $(0,12,24,48$ and 72 h) was done according to methodology established by the American Public Health Association (Doores, Salfinger \& Tortorello, 2013). $10 \mathrm{~g}$ of the fermented product were dissolved in $90 \mathrm{~mL}$ of sterile $0.1 \%$ peptone water. Successive dilutions were performed by taking $1 \mathrm{~mL}$ of the prepared solution and dissolving it in $9 \mathrm{~mL}$ of sterile peptone water, as often as necessary. Each aliquot of $1 \mathrm{~mL}$ of the prepared dilutions were served in sterile Petri dishes, and plated onto potato dextrose agar (PDA) and Man, Rogose, Sharpe (MRS) both formulated by Scharlau (Spain). Upon solidification the Petri dishes with MRS agar were incubated at $37 \pm 1^{\circ} \mathrm{C}$ in anaerobic conditions for $48 \mathrm{~h}$ for LAB count. On the other hand the Petri dishes with PDA agar were incubated at $25 \pm 1^{\circ} \mathrm{C}$ in aerobic conditions for five days for counts of yeasts (shiny, white circular colonies) and mixed yeast-bacterial consortia (blumpy, white, irregular colonies). 


\section{Physico-chemical analyses $\mathrm{pH}$ and acidity monitoring}

$2.5 \mathrm{~g}$ of previously weighed sample was mixed with $35 \mathrm{~mL}$ of $\mathrm{CO}_{2}$-free water and titrated with $\mathrm{NaOH}$ (Chemi, Italy) $0.05 \mathrm{~N}$ until pH 8.5. pH and acidity were measured using an automatic titrator T50 (Mettler- Toledo, Switzerland).

\section{Differential Scanning Calorimetry}

The procedure was carried out as reported by Buitink et al. (1996). Approximately $10 \mathrm{mg}$ of sample were placed in a sample aluminum container for this type of test, which was sealed and placed in the device under a hermetic and adiabatic environment. The thermograms were recorded between $25^{\circ} \mathrm{C}-200^{\circ} \mathrm{C}$ in a modulated system at a rate of $10^{\circ} \mathrm{C} / \mathrm{min}$, using nitrogen as a purge. A Modular DSC 2910 (TA Instruments, USA) was used with Thermal Solutions Software.

\section{Scanning Electron Microscopy (SEM)}

Samples were mounted on SEM stubs and sputter coated with gold. Specimens were examined and pictures obtained with FEI Quanta 200 Scanning Electron Microscope (Hillsboro, USA).

Preparation of ethanol extracts for determination of total flavonoids, total phenolics and antioxidant activity

About $1 \mathrm{~g}$ of sample was weighed into a $100 \mathrm{~mL}$ beaker, and $30 \mathrm{~mL}$ of ethanol ( $96 \% \mathrm{v} / \mathrm{v})$ (Chemi, Italy) were added. The beaker was covered and stirred at low speed for $24 \mathrm{~h}$ in darkness. The solution was filtered using 3hw filter paper (Sartorius, Germany) and completed quantitatively to $100 \mathrm{~mL}$ with ethanol $(96 \% \mathrm{v} / \mathrm{v})$.

\section{Total flavonoids}

$4 \mathrm{~mL}$ of distilled water, $0.3 \mathrm{~mL}$ of a $5 \% \mathrm{NaNO}_{2}$ (J.T. Baker, USA) solution and $1 \mathrm{~mL}$ of bee-pollen extract were mixed. After five minutes, $0.3 \mathrm{~mL}$ of a $10 \% \mathrm{AlCl}_{3}$ (Panreac, Spain) solution was added, and one minute later $2 \mathrm{~mL}$ of $\mathrm{NaOH}$ (Panreac, Spain) $1 \mathrm{M}$ and $2.4 \mathrm{~mL}$ of distilled water were mixed. Final solution absorbance was read at $510 \mathrm{~nm}$ with a spectrophotometer JASCO Model V-530 UV/VIS through the use of Spectra Manager software (Jasco, Italy). Results were expressed as quercetin equivalents: $\mathrm{mg}$ eq-quercetin/g bee-pollen (Almaraz-Abarca et al., 2004).

\section{Total phenolics (Folin-Ciocalteu)}

The total phenol content was estimated according to the Folin-Ciocalteu method with some modifications (Singleton, Orthofer, \& Lamuela-Raventos, 1999), using gallic acid (SigmaAldrich, USA) as a standard. Absorbance was measured with a spectrophotometer JASCO Model V-530 UV/VIS through the use of Spectra Manager software (Jasco, Italy) at $765 \mathrm{~nm}$ using water as a blank. The curve of gallic acid was plotted in a range of 0.2 to $1.0 \mathrm{mg} / \mathrm{mL}$. The results were expressed as gallic acid equivalents: $\mathrm{mg}$ eq-gallic acid/g bee-pollen (dry basis).

Trolox equivalent antioxidant activity (TEAC)

The antioxidant activity was determined through the radical ABTS reaction (Erel, 2004). The stock solution of ABTS radical cation was prepared by reacting a $7 \mathrm{mM}$ solution of the ABTS diammonium salt (Sigma-Aldrich, USA) with a $2.45 \mathrm{mM}$ solution of potassium persulfate (Sigma-Aldrich, USA). $1 \mathrm{~mL}$ of assay solution and $10 \mu \mathrm{L}$ of extract of sample were mixed and the absorbance was read at $734 \mathrm{~nm}$ after six minutes with a spectrophotometer and Spectra Manager software JASCO Model V-530 UVIVIS (Jasco, Italy). The degree of discoloration was calculated as the percentage of reduction in absorbance, which was calculated in relation to the trolox (Sigma-Aldrich, USA) equivalent concentration $(0.2-2 \mathrm{mM})$. The results were expressed as $\mu \mathrm{mol}$ trolox/g bee-pollen (dry basis).

Ferric reducing ability of plasma (FRAP)

The antioxidant activity was determined through the ferric radical complex-2,4,6-tripyridyl-s-triazine (TPTZ) reaction (Benzie \& Strain, 1996). $20 \mu \mathrm{L}$ of extract, $450 \mu \mathrm{L}$ of FRAP solution (a mixture of a buffer acetate-acetic acid (Sigma-Aldrich, USA), TPTZ (Sigma-Aldrich, USA) and $\mathrm{FeCl}_{3}$ (Sigma-Aldrich, USA) solutions) and $735 \mu \mathrm{L}$ of distilled water were mixed and kept in darkness for thirty minutes at $40^{\circ} \mathrm{C}$. Absorbance was measured at $593 \mathrm{~nm}$ with a spectrophotometer and Spectra Manager software JASCO Model V-530 UV/VIS (Jasco, Italy) at $765 \mathrm{~nm}$. The results were expressed as $\mu \mathrm{mol}$ trolox/g bee-pollen (dry basis). 


\section{Statistical analysis}

Data from produced acidity and viable cell count were plotted and obtained curves were automatically smoothed with the use of Microsoft Excel $^{\circ}$ graphics tools. Statistical analysis was performed with an ANOVA test to find any differences between untreated pollen and fermented products. The quantitative variables of mean and standard deviation were compared with the Tukey test with a significance level of $95 \%$. On the other hand, for the selection of the best thermal treatment, a total ranking method was used, as described by Pavan \& Worth (2008). Total order ranking was used as a technique to rank all treatments on a basis of the physical chemical results. The criteria values are combined into a global ranking index, which may be calculated by employing such functions as utility and convenience (or desirability). Since criteria values come from response variables having different units, a logistic sigmoid transformation function had been previously employed in order to obtain standardized data, making each variable equally important in the analysis. Then, the overall utility of the i-th treatment was calculated as shown in equation 1.

$$
U_{i}=\sum_{j=1}^{p} w_{j} \cdot t_{i j}
$$

Where $p$ is the total number of criteria, $w$ is the assigned weight for each criterion (between 0 and 1), and $t$ is the numerical result of the sigmoid transformation for the j-th criterion. The sum of all weights must be 1 . In our study, each criterion was equally weighed assigning them a value of 0.25 . On the other hand, the overall convenience of the i-th treatment was obtained as shown in equation 2.

$$
D_{i}=t_{i 1}^{w_{1}} \cdot t_{i 2}^{w_{2}} \cdot \ldots \cdot t_{i p}^{w_{p}}
$$

Both convenience and utility range from 0 to 1 , the higher being the better. From eq. 1 and 2 , convenience is established to be a more severe function than utility. If a transformation result of any criterion is 0 , the convenience will also be 0 . Once results of convenience and utility have been obtained for all treatments, they are ordered sequentially. The best treatment will be that having the highest value for both functions. Statistical analysis were carried out using the MATLAB (The Mathworks, ver. 7.14, 2012) statistical package and the DART (Pavan \& Worth 2008) (Decision Analysis and Ranking Techniques) software (Talete srl, Italia).

\section{RESULTS}

\section{Monitoring of fermentation}

Each fermentation was monitored through the measuring of the acidity produced and the number of colony forming units (CFU). The acidity produced is shown in Fig. 1. The fermentation with $\mathrm{Choozit}^{\oplus}$ reached the highest acidity values, being higher than $200 \mathrm{meq} / \mathrm{kq}$ after $72 \mathrm{~h}$. Meanwhile, L. plantarum and the consortium between the ATCC strains of S. cerevisiae and $L$. plantarum reached an acidity produced of 140 $\mathrm{meq} / \mathrm{kg}$ at 72 hours of fermentation.

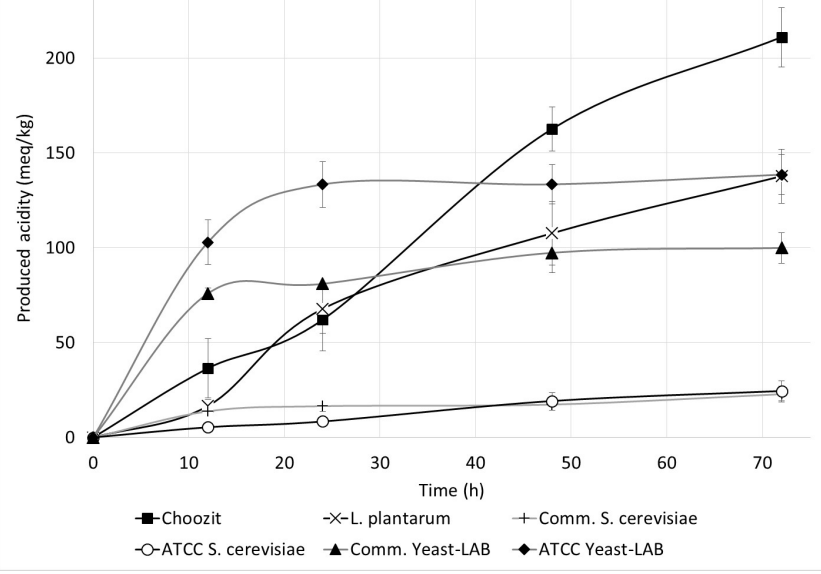

Fig. 1. Bee-pollen monitoring of fermentation by produced acidity.

On the other hand, the viable cell count along the fermentation treatments is shown in Fig.2, with all tests having an initial cell count of $8 \log _{10}(\mathrm{CFU} / \mathrm{g})$. With respect to the fermentation carried out with $L$. plantarum, the population of viable microorganisms stayed above 8 and $9 \log _{10}$ (CFU/g), showing a high adaptability to the substrate. Meanwhile, the ATCC consortium showed a population reduction throughout the fermentation process until reaching a value of 


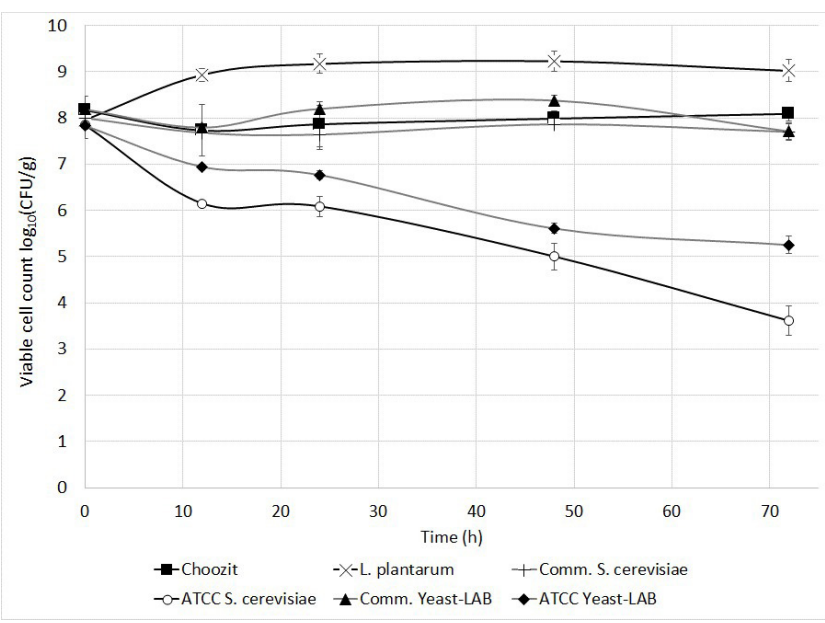

Fig. 2. Bee-pollen monitoring of fermentation by viable cell count.

$5 \log _{10}$ (CFU/g) at the end of the process. Additionally, the ATCC yeast also showed a similar tendency, reaching a viable cell count of less than $4 \log _{10}$ (CFU/g). In this case, commercial cultures evidently adapt better to the substrate, keeping their viable population stable over time.

\section{Final product characterization}

Differential Scanning Calorimetry

Since the external structure of the bee-pollen grain is highly rigid, one of the objectives of this work was to evaluate if the fermentation favors the modification of the exine layer, which in turn would help to release the components that are inside, making them more available. The use of the DSC would then serve as a way to indirectly measure the degree of grain break through the variation in heat flow. In this sense, the calorimetric profile of bee-pollen, bee-bread and fermented samples is shown in Fig. 3.

In addition, Tab. 1 shows the enthalpy values obtained for each sample analyzed. There was a noticeable increase in enthalpy values, from $50.2 \mathrm{~J} / \mathrm{g}$ in bee-pollen to $600.4 \mathrm{~J} / \mathrm{g}$, in the fermented product using the commercial yeast-LAB consortium.

\section{Scanning electron microscopy}

Different SEM microphotographs were taken of bee-pollen, bee-bread and fermented products, which are presented in Fig. 4. In general, a structural modification of the grain can be observed, in fermented products and that may be linked to results of enthalpies by DSC which showed an increase in the heat flow with respect to bee-pollen. This indicates that a slight modification of exine was performed by microorganisms along the fermentation process. Effect of fermentation on the content of bioactive compounds and antioxidant activity The results of bioactive compounds and antioxidant activity of $L A B$ fermentation are shown in Tab. 2. In general, a significant increase can be observed in phenolic compound content in fermented products in comparison to bee-pollen and bee-bread, where the commercial mix had the highest result. On the contrary, total flavonoids showed no significant differences between bee-pollen, bee-bread and most of the

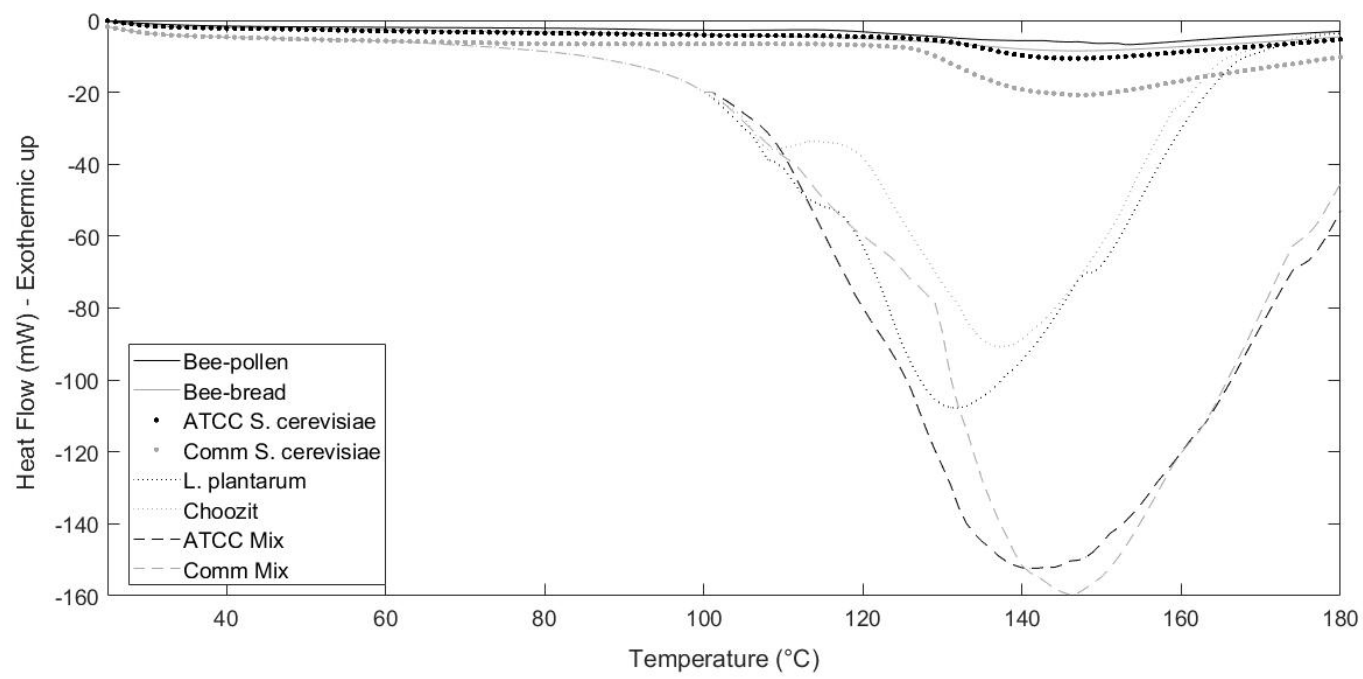

Fig. 3. DSC profile of raw bee-pollen, bee-bread and fermented products. 


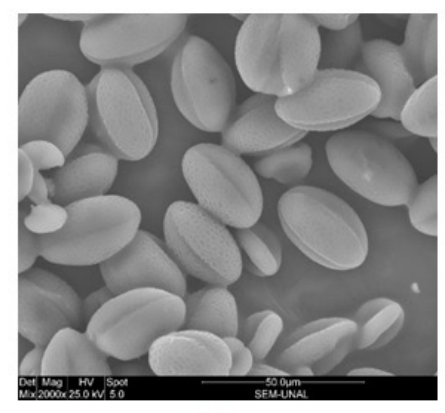

(a)

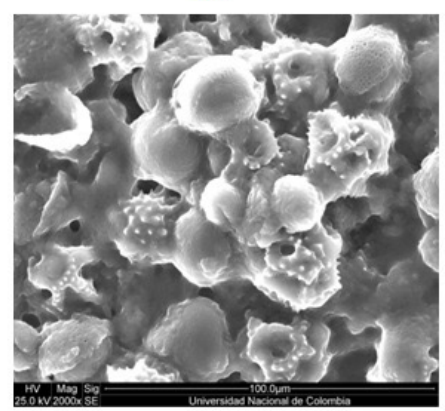

(d)

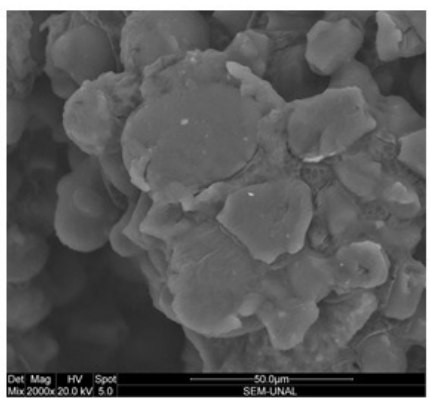

(b)

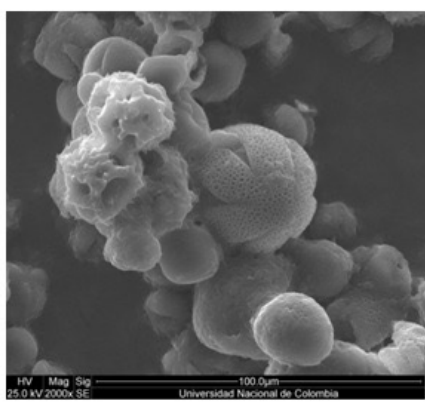

(e)

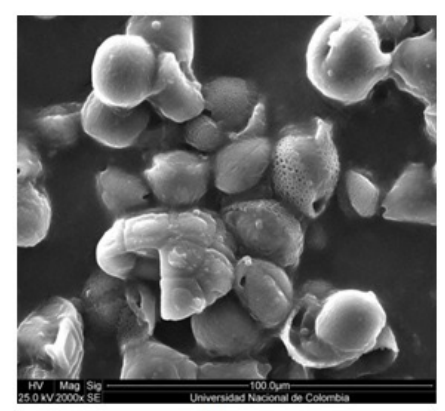

(c)

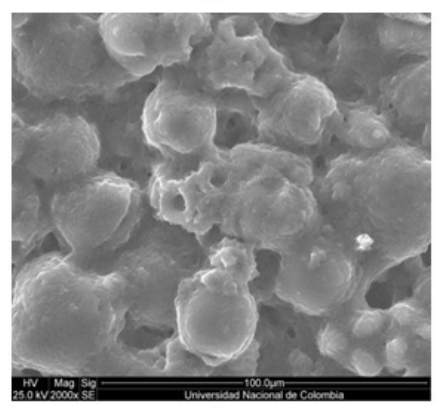

(f)

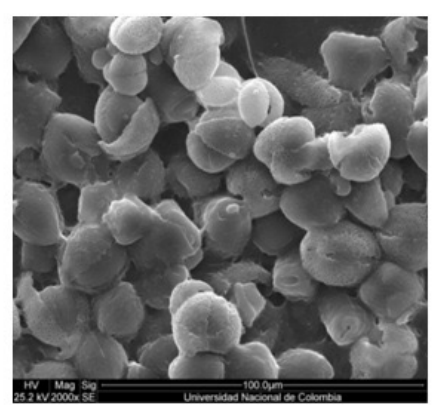

(g)

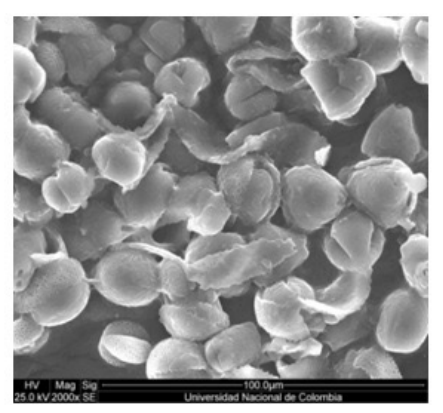

(h)

Fig. 4. SEM microphotographs for (a) fresh bee-polen, (b) bee-bread, and bee-pollen fermented by (c) Choozit ${ }^{\oplus}$, (d) L. plantarum, (e) ATCC Saccharomyces cerevisiae, (f) Commercial Saccharomyces cerevisiae, (g) ATCC Mix and, (h) Commercial Mix. (Zoom 2000X)

Table 1.

DSC results for bee-pollen, bee-bread and fermented bee-pollen

\begin{tabular}{ccc}
\hline Product & Peak temperature $\left({ }^{\circ} \mathrm{C}\right)$ & $\begin{array}{c}\text { Peak integration } \\
\text { (Enthalpy }(\mathrm{J} / \mathrm{g})\end{array}$ \\
\hline Bee-pollen & 155 & 50.2 \\
Bee-bread & 150 & 67.2 \\
L. plantarum & 130 & 312.4 \\
Choozit & 139 & 385.2 \\
ATCC Saccharomyces & 144 & 75.9 \\
$\begin{array}{c}\text { cerevisiae } \\
\text { Commercial Saccharomyces } \\
\text { cerevisiae }\end{array}$ & 145 & 100.2 \\
ATCC Mix & 140 & 585.8 \\
Commercial Mix & 144 & 600.4 \\
\hline
\end{tabular}


Bioactive content and antioxidant activity of fermented products

\begin{tabular}{|c|c|c|c|c|}
\hline Sample & $\begin{array}{c}\text { Total phenolics } \\
\text { (mg GAE/g) }\end{array}$ & $\begin{array}{c}\text { Total flavonoids } \\
\text { (mg QE/g) }\end{array}$ & $\begin{array}{c}\text { FRAP } \\
(\mu \mathrm{mol} \text { TROLOX/و) }\end{array}$ & $\begin{array}{c}\text { TEAC } \\
(\mu \mathrm{mol} \text { TROLOX/g) }\end{array}$ \\
\hline $\begin{array}{c}\text { Fresh } \\
\text { bee-pollen }\end{array}$ & $14.96 \pm 2.11$ bc & $4.99 \pm 1.79$ bcd & $58.48 \pm 5.55$ & $60.83 \pm 9.86$ b \\
\hline Bee-bread & $14.99 \pm 2.47$ bc & $3.73 \pm 0.40^{b}$ & $30.78 \pm 4.76$ & $42.70 \pm 5.56 \mathrm{ab}$ \\
\hline Choozit $^{\oplus}$ & $18.89 \pm 2.24 \mathrm{~cd}$ & $3.93 \pm 0.06$ & $58.63 \pm 4.79 d$ & $55.11 \pm 1.90$ \\
\hline L. plantarum & $13.18 \pm 0.15 b$ & $3.23 \pm 0.05$ & $38.22 \pm 2.67 c$ & $58.18 \pm 6.66^{b}$ \\
\hline $\begin{array}{c}\text { ATCC } \\
\text { S. cerevisiae }\end{array}$ & $10.49 \pm 0.58$ & $2.94 \pm 0.19$ & $22.16 \pm 3.77 \mathrm{a}$ & $39.02 \pm 5.28$ a \\
\hline $\begin{array}{l}\text { Commercial } \\
\text { S. cerevisiae }\end{array}$ & $13.80 \pm 0.94$ b & $3.00 \pm 0.34 \mathrm{ab}$ & $31.31 \pm 5.25$ bc & $38.66 \pm 5.66$ a \\
\hline ATCC Mix & $18.50 \pm 0.31^{d}$ & $4.94 \pm 0.18^{d}$ & $75.90 \pm 4.54 \mathrm{e}$ & $84.66 \pm 2.23^{c}$ \\
\hline $\begin{array}{c}\text { Commercial } \\
\text { Mix }\end{array}$ & $19.56 \pm 1.25^{d}$ & $4.44 \pm 0.24^{c}$ & $73.22 \pm 5.41 \mathrm{e}$ & $84.02 \pm 4.28^{c}$ \\
\hline
\end{tabular}

$a=0.05$ significance level was considered.

induced fermented products; however, fermentation with ATCC S. cerevisiae had a significantly lower content. Finally, for both antioxidant activity techniques, fermented products with either ATCC or commercial bacterial and yeast cultures showed significant increases compared to other treatments and also bee-pollen and bee-bread.

Different letters in the same column mean signif- icant differences among treatments according to the Tukey test.

\section{Selection of the best treatment}

A total ranking function model was used in order to visualize the effectiveness of each treatment and to carry out a selection of the best treatments in an objective manner. The results obtained are presented in Fig. 5.

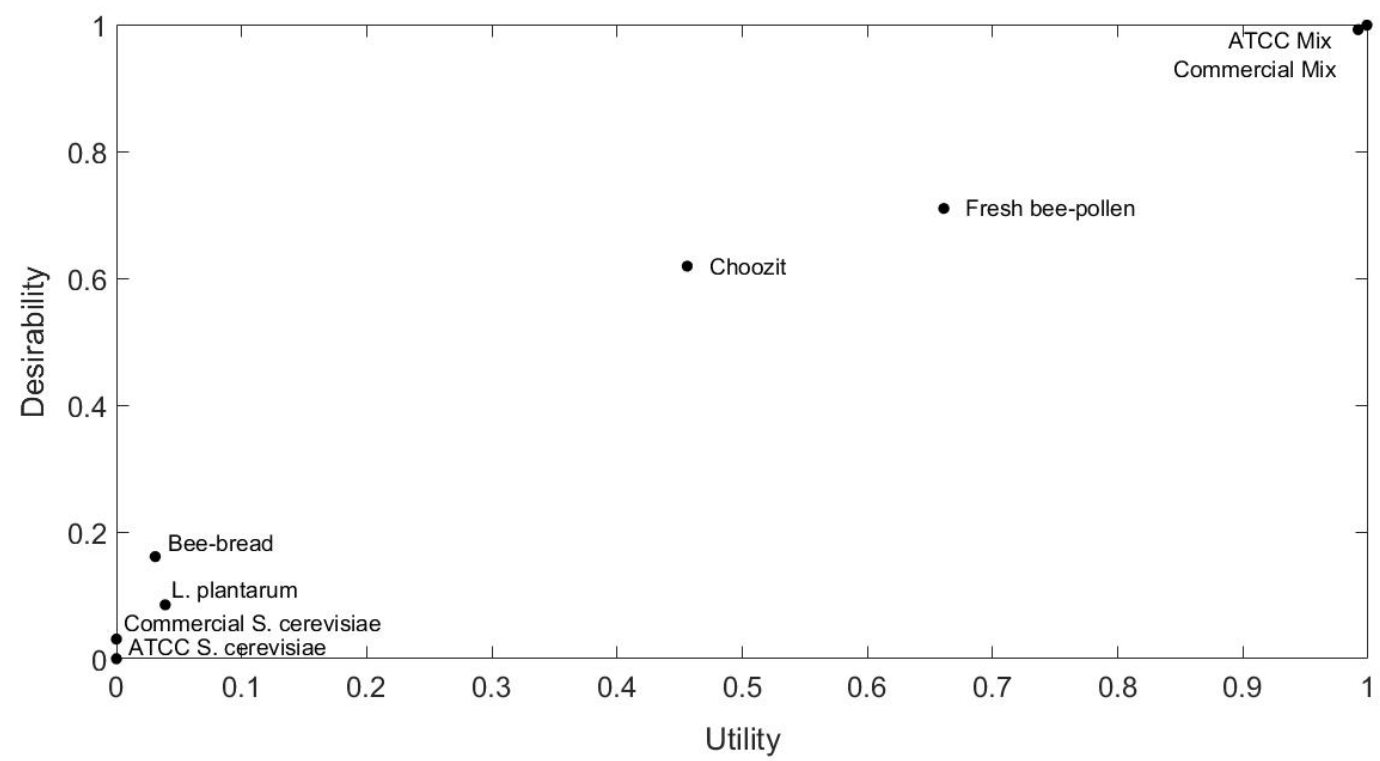

Fig. 5. Result of total ranking method. 


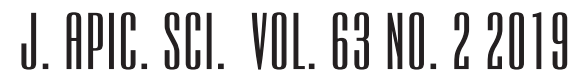

\section{DISCUSSION}

\section{Monitoring of fermentation}

Although at the end of the bioprocess there was no significant difference in the acidity produced in all treatments ( $p=0.87$ ), it is evident that the consortium formed by the ATCC strains rapidly produced acids in the first twenty hours, until reaching its value maximum that remained stable until the end of the measurement. This tendency contrasts with the fermentation carried out only with L. plantarum, which showed a growing acid production during the entire measurement time. On the other hand, as expected, fermentations carried out only with S. cerevisiae, either ATCC or commercial, showed little acid production, with values lower than 30 $\mathrm{meq} / \mathrm{kg}$ for both treatments. Finally, the fermentation with the consortium of commercial microorganisms S. cerevisiae - Choozit ${ }^{\oplus}$ revealed significantly lower acid production $(p<0.05)$ in comparison to the previous mentioned treatments, reaching a maximum of $100 \mathrm{meq} / \mathrm{kg}$. In this sense, a similar tendency was observed here in comparison to the ATCC consortium due to the rapid production of acid during the first $20 \mathrm{~h}$ and then showing a slight growth until 48 h. The production of acids using the consortia is moderate, which makes it a valid alternative to the fermentation process, considering that a high acidity may have an impact on the quality and stability of the product under storage. It is also evident that the inclusion of yeast helps to regulate acid production, which in general terms justifies the use of both cultures in the bioprocess.

Although L. plantarum showed appropriate growth, when it was used to form a consortium with $S$. cerevisiae a negative effect was observed in the resulting viable cell count. The comparison of these results with the observed in the acid production indicates that the consortium between used ATCC LAB and yeast caused a rapid increase in acid production until reaching a maximum at $20 \mathrm{~h}$, and then cell death happened possibly due to high lactic acid levels. In contrast, the bioprocess made only with L. plantarum showed that the population is constant over time and this favored the production of acid, only reaching the same maximum value of acidity production after $72 \mathrm{~h}$ of treatment. In contrast, the fermentations using the commercial strain of $S$. cerevisiae, Choozit ${ }^{\oplus}$, or the consortium between the commercial mix of $S$. cerevisiae - Choozit $^{\oplus}$ had no significant differences in viable cells until the final point of measurement ( $p=0.83)$, keeping a count of $8 \log _{10}$ (CFU/g) during the treatment. These results, added to those obtained in the acid production, confirm that the consortium of commercial cultures is an interesting alternative to be used in bee-pollen fermentation.

The fact that Choozit ${ }^{\circledast}$ has shown an appropriate growth and acid production indicates a synergy between the combinations of microorganisms present in this culture. In particular, the presence of Lactobacillus delbrueckii subsp. lactis in Choozit $^{\oplus}$ would then exert a positive effect on fermentation, by stimulating a faster growth of the other microorganisms over the same period and a more rapid adaptation to the environment. The ssp. lactis can be phenotypically distinguished from other for its more extensive ability to metabolize carbohydrates, including those of vegetable origin such as maltose, mannose, sucrose and trehalose (Kafsi et al., 2014). In fact, a strain of L. delbrueckii has been already reported as an effective culture for bee-pollen fermentation (Misiewicz, Kieliszek, \& Czarniak, 2015).

Alternatively, a previous research which used Lactobacillus acidophilus for bee-pollen fermentation, found that after $24 \mathrm{~h}$ the cell viability began to descend (Fuenmayor, 2009). In our study, L. plantarum showed satisfactory acid production. The difference in the results generated by the two bacteria L. plantarum and $L$. acidophillus is probably due to the metabolic route followed. L. acidophillus is a homofermentative bacterium, which preferably uses glucose as energy source and performs the fermentative process by glycolysis or the Embden-MeyerhofParnas (EMP) mechanism. L. plantarum follows the same route using the same substrate or can also follow the hexose-monophosphate route (Hexose Monophosphate Shunt - HMS) in which 
hexose and pentose may be used (Nielsen, John, \& Liden, 2003). With greater availability of nutrients, L. plantarum is more likely to increase its biomass by performing the bioprocess more effectively and by making a better use of nutrients (Salazar, 2014). This microorganism can tolerate lower $\mathrm{pH}$ values than most bacteria, and therefore its survival time in the substrate is higher. This trend has already been found in silages of such plant products as maize, which has different complex carbon sources (Ortiz, 2007).

Finally, $\mathrm{pH}$ values for all fermentations ranged from 3.57 to 4.01 with a slight reduction compared to fresh bee-pollen (4.16). The low $\mathrm{pH}$ variability reflects that this is a poor indicator for monitoring this type of reaction due to the substrate composition's high complexity involving a great diversity of such chemical species as mineral and organic salts and organic acids. These changes due to bacterial metabolism are able to generate chemical equilibriums that lead to the formation of buffers that enables the direct correlation of the $\mathrm{pH}$ reading with the increase of the acid concentration in the medium (Fuenmayor, 2009).

\section{Final product characterization}

\section{Differential Scanning Calorimetry}

It is possible to notice that in comparison to raw bee-pollen or bee-bread, induced fermented products had higher heat fluxes, which suggest a modification in the grain structure. In general, until $100^{\circ} \mathrm{C}$ no significant changes were observed in the thermal profiles, which are usually due to the evaporation of water. From this temperature, the changes in the profiles were evident when fresh bee-pollen showed the highest thermal stability, followed by the bee-bread and bee-pollen fermenting with yeasts. Meanwhile, notorious thermal instability was found in the bioprocesses made with lactic acid bacteria and the consortia of yeast and bacteria. This indicates that the fermentation processes carried out mainly with these consortia favors an exine degradation, which in turn causes thermal instability of the grain and eventual release of components.
An analysis of the enthalpy values of each measurement, which were obtained by integrating the peak and dividing by the bee-pollen mass, allows the extent of the modification in the bee-pollen structure to be indirectly quantified. The bibliographic reports mention that the temperature of the peak is proportional to the thermal stability (Gabbott, 2008). In this case, bee-pollen is observed to have the highest peak temperature, which could mean that its unaltered structure was more stable, corroborated by comparison with enthalpy values. In addition, bee-bread showed little variation in peak temperature and enthalpy in comparison to bee-pollen; this might indicate that the examined bee-bread could not have had a notorious structural modification. In the case of induced fermented products, the temperature at which the maximum heat flow occurred was variable and depended on the type of culture employed, however in commercial cultures this temperature ranged between 139 and $145^{\circ} \mathrm{C}$. Meanwhile, for the ATCC strains, a maximum heat flux was observed at temperatures between 130 and $144^{\circ} \mathrm{C}$. Therefore, the bee-pollen fermented by yeast-LAB consortium may undergo more intense structural modifications in comparison to the process carried out by a single microorganism, which in spite of achieving also an alteration of the bee-pollen structure, could not reach the same effectiveness.

Effect of fermentation on the content of bioactive compounds and antioxidant activity

The bioactive characterization of bee-pollen and bee-bread showed no significant differences in the content of flavonoids and total phenolics, as also in the antioxidant activity by FRAP and TEAC. With regard to the content of total phenolics, significant differences were found in some fermentation treatments with respect to fresh bee-pollen and bee-bread. Among them, significantly higher values were found for consortia made with ATCC and commercial mixtures, reaching average values of up to $19.56 \mathrm{mg} \mathrm{GAE} / \mathrm{g}$, which represents an increase of $31 \%$ with respect to fresh bee-pollen. In general, the individual cultures 
did not show any significant difference with respect to the bee-pollen, however the content of phenolic compounds for the fermentation with the yeast ATCC S. cerevisiae was found to decrease to almost 30\%. One possible reason for this decline is that the yeasts may have consumed these compounds for the development of their metabolic functions.

In addition, the average total flavonoid content tended to decrease in the fermented products compared to bee-pollen, and even this reduction was also found in the bee-bread. Those reductions were representative for fermentation with both ATCC and commercial yeast, being $41 \%$ and $40 \%$ lower than the average content for bee-pollen, respectively. Under this consideration, the treatments that had the least impact on the average result of the flavonoid content were those made with the yeast-LAB consortiums, presenting similar content levels to fresh bee-pollen, but higher than the average reported for bee-bread.

The results of antioxidant activity by FRAP showed diverse effects. Initially, no significant differences were found between bee-pollen and products fermented with Choozit ${ }^{\oplus}$ for this measurement. Meanwhile, antioxidant activity showed a reduced level between 35-47\%, with respect to fresh bee-pollen, for bee-bread and products fermented using yeasts or $L$. plantarum. In contrast, antioxidant activity for both yeast-LAB consortia increased significantly reaching levels higher than 30\%. Antioxidant activity is not always directly proportional to the polyphenol content, since other such compounds as carotenoids, vitamins, aminoacids and other secondary metabolites also exert a considerable effect on the overall anti-radical ability (Mărghitaş et al., 2009).

Finally, the antioxidant TEAC activity showed similar trends to those previously described with the FRAP technique. There were no significant differences in the average values obtained for bee-pollen, bee-bread and products fermented with Choozit ${ }^{\oplus}$ or L. plantarum. However, significant a reduction close to $36 \%$ was found for products fermented with yeasts. As reported for FRAP, the highest values of antioxidant activity with the TEAC technique were found when the yeast-LAB consortia were used, in which case there was a significant increase of up to $39 \%$.

\section{Selection of the best treatment}

Based on the evidence of the results, the used yeast-LAB consortia clearly showed a substantial improvement in the characteristics of the fermented products. From the obtained result it is possible to establish that the fermentations carried out using only yeasts are neither useful nor desirable, since as mentioned throughout this work, they do not favorably impact the bioactive characteristics, even with values significantly lower than those found for bee-pollen. In the case of bee-bread and the product fermented with L. plantarum, there is a low utility and desirability due to the decrease antioxidant activity compared to bee-pollen.

On the other hand, the product fermented with Choozit ${ }^{\oplus}$ has an intermediate utility and desirability, which although appears to be an effective process alternative, the high production of acid and the decrease in the flavonoid content are punished in the model. Clearly, all those treatments with lower utility and desirability values compared to bee-pollen are undesirable and useless, since they would be detrimental to the quality of the final product compared to the raw material. Based on the above, the best results were established for the treatments using the ATCC or the commercial consortia, offering better results than even the bee-bread evaluated in this research. In this sense, as can be observed, the differences in the reported values of utility and desirability for both cases are negligible, with which it can be established that using either of the two consortia leads to a similar result. This indicates that under controlled laboratory conditions an improved lactic-acid fermented product can be obtained in relation to the bee-pollen and bee-bread examined in this study. However, at a productive level it is much more profitable and economical to use commercially available cultures than ATCC strains. 


\section{ACKNOWLEDGEMENTS}

The authors thank the Administrative Department of Science, Technology and Innovation, COLCIENCIAS, the companies Apiarios el Pinar and Apiario los Cerezos and the Institute of Food Science and Technology and Department of Chemical and Environmental Engineering at the Universidad Nacional de Colombia.

\section{REFERENCES}

Almaraz-Abarca, N., Campos, M., Ávila-Reyes, J., Naranjo-Jiménez, N., Herrera-Corral, J., GonzálezValdez, L. (2004). Variability of antioxidant activity among honeybee-collected pollen of different botanical origin. Interciencia, 29(10), 1-12.

Almeida-Muradian, L., Pamplona, L., Coimbra, S., \& Barth, O. (2005). Chemical composition and botanical evaluation of dried bee pollen pellets. Journal of Food Composition and Analysis, 18(1), 105-111. https://doi. org/10.1016/j.jfca.2003.10.008

Andelkovic, B., Jevtic, G., Mladenovic, M., Markovic, J., Petrovic, M., Nedic, N. (2012). Quality of pollen and honey bee bread collected in spring. Journal of Hygienic Engineering and Design, 1, 275-277.

Avallone, S., Guyot, B., Brillouet, J., Olguin, E., Guiraud, J. (2001). Microbiological and Biochemical Study of Coffee Fermentation. Current Microbiology, 42(4), 252-256. https://doi.org/10.1007/s002840110213

Benzie, F., \& Strain, J. (1996). The Ferric Reducing Ability of Plasma (FRAP) as a Measure of "Antioxidant Power": The FRAP Assay. Analytical Biochemistry, 239(1), 70-76. https://doi.org/10.1006/ abio.1996.0292

Bogdanov, S. (2011). The Bee Pollen Book. Muehlethurnen, Switzerland: Bee Product Science.

Buitink, J., Walters-Vertucci, C., Hoekstra, F., \& Leprince, O. (1996). Calorimetric Properties of Dehydrating Pollen. Plant Physiology, 177(1), 235-242. https:// doi.org/10.1104/pp.111.1.235

Campos, M., Frigerio, C., Lopes, 1., \& Bogdanov, S. (2010). What is the future of Bee-Pollen? Journal of ApiProduct and ApiMedical Science, 2(4), 131-144.

Del Risco, C., Pérez, A., Álvarez, V., Rodríguez, G., Leiva, V., Puig, Y., García, R. (2012). Bacterias ácido-lácticas para ensilar polen apícola. Revista CEN/C Ciencias Biológicas, 43(1), 17-21.

Doores, S., Salfinger, Y., \& Tortorello, M. (2013). Compendium of Methods for the Microbiological Examination of Foods. Washington D.C.: American Public Health Association.

Erel, O. (2004). Novel automated direct measurement method for total antioxidant capacity using a new generation, more stable ABTS radical cation. Clinical Biochemistry, 374), 277-285, https://doi. org/10.1016/j.clinbiochem.2003.11.015

Fuenmayor, C. (2009). Aplicación de bioprocesos en polen de abejas para el desarrollo de un suplemento nutricional protéico. Bogotá: Universidad Nacional de Colombia.

Fuenmayor, C., Zuluaga, C., Diaz, C., Quicazán, M., Cosio, M., Mannino, S. (2014). Evaluation of the physicochemical and functional properties of Colombian bee pollen. Revista MVZ Córdoba, 1911), 4003-4014.

Gabbott, P. (2008). Principles and Applications of Thermal Analysis. Oxford: Blackwell Publishing Ltd.

Gilliam, M. (1979a). Microbiology of pollen and bee bread: The genus Bacillus. Apidologie, 10(3), 269274.

Gilliam, M. (1979b). Microbiology of pollen and bee bread: The yeasts. Apidologie, 191), 43-53.

Kafsi, H., Binesse, J., Loux, V., Buratti, J., Boudebbouze, S., Dervyn, R., Kennedy, S...., van de Guchte, M. (2014). Lactobacillus delbrueckii spp. lactis and ssp. bulgaricus. a chronicle of evolution in action. BMC Genomics, 15, 407-418. https://doi.org/10.1186/14712164-15-407 


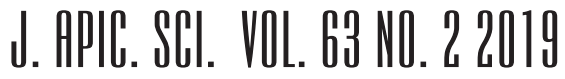

Kieliszek, M., Piwowarek, K., Kot, A., \& Chlebowska, A. (2018). Pollen and bee bread as new health-oriented products: A review. Trends in Food Science and Technology, 71, 170-180, https://doi.org/10.1016/j. tifs.2017.10.021

Leja, M., Mareczek, A., Wyżgolik, G., Klepacz-Baniak, J., Czekońska, K. (2007). Antioxidative properties of bee pollen in selected plant species. Food Chemistry, 1001), 237-240. https://doi.org/10.1016/j.foodchem.2005.09.047

Lopitz-Otsoa, F., Rementeria, A., Elguezabal, N., \& Garaizar, J. (2006). Kefir: A symbiotic yeast-bacteria community with alleged healthy capabilities. Revista Iberoamericana de Micología, 23(2), 67-74.

Mărghitaş L., Stanciu, O., Dezmirean, D., Bobiş, O., Popescu, O., Bogdanov, S., Campos, M. (2009). In vitro antioxidant capacity of honeybee-collected pollen of selected floral origin harvested from Romania. Food Chemistry, 715(3), 878-883. https://doi. org/10.1016/j.foodchem.2009.01.014

Misiewicz, A., Kieliszek, M., \& Czarniak, K. (2015). New strain of Lactobacillus delbrueckii bacteria and its use for the production of bee pollen. Patent: W02015093997.

Nielsen, J., John, V., \& Liden, G. (2003). Bioreaction Engineering Principles. New York: Plenum Publishers.

Ortiz, L. (2007). Evaluación del Potencial de Producción de Bacteriocinas de Lactobacillus aislados de Ensilajes a base de Maíz. Bogotá: Universidad Nacional de Colombia.

Pavan, M., \& Worth, A. (2008). A set of case studies to illustrate the applicability of DART (Decision Analysis by Ranking Techniques) in the ranking of chemicals. Luxemburg: IRC Scientific and Technical Reports.

Salazar-González, C., \& Díaz-Moreno, C. (2016). The nutritional and bioactive aptitude of bee pollen for a solid-state fermentation process. Journal of Apicultural Research, 55(2), 161-175. https://doi.org/10.10

\section{0/00218839.2016.1205824}

Salazar, C. (2014). Evaluación de diferentes condiciones del proceso de fermentación en fase sólida de polen apícola. Bogotá: Universidad Nacional de Colombia.

Schwan, R., \& Wheals, A. (2004). The microbiology of cocoa fermentation and its role in chocolate quality. Critical Reviews in Food Science and Nutrition, 44(4), 1-17. https://doi. org/10.1080/10408690490464104

Singleton, V., Orthofer, R., \& Lamuela-Raventos, R. (1999). Analysis of total phenols and other oxidation substrates and antioxidants by means of Folin-Ciocalteu reagent. Methods in Enzymology, 299, 152-178. https://doi.org/10.1016/S00766879(99)99017-1

Teoh, A., Heard, G., \& Cox, J. (2004). Yeast ecology of Kombucha fermentation. International Journal of Food Microbiology, 95(2), 119-126. https://doi. org/10.1016/j.ijfoodmicro.2003.12.020

Vamanu, A., Vamanu, E., Drugulescu, M., Popa, O., Câmpeanu, G. (2006). Identification of a Lactic Bacterium Strain Used for Obtaining a Pollen-Based Probiotic Product. Turkish Journal of Biology, 30, 75-80.

Vamanu, A., Vamanu, E., Popa, O., Campeanu, G., Albulescu, R., Drugulescu, M., Nita, S., Babeani, N. (2008). Obtaining of a symbiotic product based on lactic bacteria, pollen and honey. Pakistan Journal of Biological Sciences, 77(4), 613-617.

Vamanu, E., Vamanu, A., Popa, O., \& Babeanu, N. (2010). The antioxidant effect of a functional product based on probiotic biomass, pollen and honey. Animal Science Biotechnology, 43(1), 331-336.

Vasquez, A., Olofsson, T., Vásquez, A., \& Olofsson, T. (2009). The lactic acid bacteria involved in the production of bee pollen and bee bread. Journal of Apicultural Research, 48(3), 189-195, https://doi. org/10.3896/IBRA.1.48.3.07

Zuluaga, C., Serrato, J., \& Quicazan, M. (2015). Bee- 


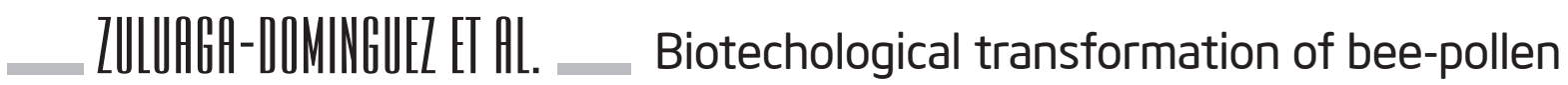

Pollen Structure Modification by Physical and Biotechnological Processing: Influence on the Availability of Nutrients and Bioactive Compounds. Chemical Engineering Transactions, 43, 79-84. https://doi.org/10.3303/CET1543014 